\title{
Occurrence of Extra Roots in Permanent Mandibular Molars: A Cone Beam Computed Tomography Study
}

\author{
Dr. Anil Chakradhar, ${ }^{1}$ Dr. Manisha Nepal, ${ }^{1}$ Dr. Siras Pradhan, ${ }^{1}$ \\ Dr. Nisha Acharya, ${ }^{2}$ Dr. Pratibha Poudel ${ }^{3}$ \\ ${ }^{1}$ Department of Conservative Dentistry and Endodontics, Kathmandu University School of Medical Sciences, \\ Dhulikhel, Kavrepalanchok, Nepal; \\ ${ }^{2}$ Department of Conservative Dentistry and Endodontics, Institute of Medicine (IOM), Maharajgunj Campus, Dental Teaching Hospital; \\ Maharajgunj, Kathmandu, Nepal; \\ ${ }^{3}$ Department of Oral and Maxillofacial Pathology, Kathmandu University School of Medical Sciences, \\ Dhulikhel, Kavrepalanchok, Nepal.
}

\begin{abstract}
Introduction: Permanent mandibular first and second molars may display extra roots namely radix entomolaris and radix paramolaris which may have implications in endodontic treatment outcome, if missed.

Objective: To evaluate the occurrence of extra roots in permanent mandibular first and second molars in a sample of Nepalese population.

Methods: This analytical cross-sectional study was done at Dhulikhel hospital. Convenience sampling technique was utilised for data collection of 773 CBCT images. Images from June 2018 to June 2020 were retrospectively screened for presence of fully erupted bilateral mandibular first and second molars. Presence of extra roots were recorded and laterality, gender, and racial variations were analysed by Fisher's exact test and Chi-square test using SPSS v.20.

Results: For mandibular first molars, out of 517 patients, 65 (11.38\%) had radix entomolaris: 38 (13.2\%) female and 27 (9.54\%) male. Among 38 females; occurrence was 21 (7.3\%) bilateral, 16 (5.56\%) unilateral right and 1 (0.34\%) unilateral left side. Likewise, among 27 males, the occurrence was 15 (5.3\%) bilateral, 6 (2.1\%) unilateral right and 6 (2.1\%) unilateral left side. Regarding races, 50 (14.6\%) were Mongoloids and 15 (6.6\%) were Aryans. No radix paramolaris was found in mandibular first molars. For mandibular second molars, out of 623 patients, radix entomolaris and paramolaris were observed in $0.8 \%$ and $0.48 \%$ respectively.

Conclusion: The overall occurrence of radix entomolaris in mandibular first and second molars was found to be $11.38 \%$ and $0.8 \%$, respectively. Practitioners should be aware of these unusual variations to avoid iatrogenic mishap due to missed canal.

Keywords: Cone beam computed tomography; radix entomolaris; radix paramolaris.
\end{abstract}

\section{INTRODUCTION}

Mandibular first and second molars usually have two roots: one mesial and the other distal. ${ }^{1}$ However, these teeth might exhibit variations with the presence of an extra root. ${ }^{2}$ This extra root when present distolinugally is known as radix entomolaris (RE). ${ }^{3}$ Very rarely, an additional root can occur mesiobuccally known as radix paramolaris (RP)..$^{3-5}$

In endodontics, knowledge of root and canal anatomy is one of the important factors that determine the prognosis of

Correspondence
Dr. Anil Chakradhar
Email: anil254413@gmail.com
Citation

Chakradhar A, Nepal M, Pradhan S, Acharya N, Poudel P. Occurrence of Extra Roots in Permanent Mandibular Molars: A Cone Beam Computed Tomography Study. J Nepal Soc Perio Oral Implantol. 2021 Jan-Jun;5(9):29-33. treatment. Failure of root canal treatment (RCT) is mostly due to incomplete debridement from the root canal system and missed canals which occurs when clinician is unable to identify all the possible roots present including extra roots. ${ }^{2}$

Due to wide variations in tooth anatomy in different racial and ethnic groups, this is a topic of interest for various researchers. ${ }^{6}$ Thus, this study aims to evaluate the occurrence of anatomical variations in mandibular first and second molars by using cone beam computed tomography (СBCT).

\section{METHODS}

This analytical cross-sectional study was designed and conducted using patient's CBCT images that had previously been taken in the Department of Oral Medicine and Radiology, Kathmandu University School of Medical Sciences - Dhulikhel Hospital. The study was approved by KUSMS-IRC (08/21). The sample size was calculated by:

This is an open access journal, and articles are distributed under the terms of the Creative Commons Attribution CC BY 4.0 Licence. 
Sample size $(\mathrm{n}) \quad=\mathrm{Z}_{1-\alpha / 2}^{2} \mathrm{X} p(1-\mathrm{p}) / \mathrm{d}^{2}$

$$
\begin{aligned}
& =1.96^{2} \times 0.5(1-0.5) / 0.05^{2} \\
& =385
\end{aligned}
$$

where, $\mathrm{Z}_{1-\alpha / 2}=1.96$ at $95 \%$ confidence interval; $\mathrm{p}=50 \%$ expected prevalence of variations in mandibular molars was taken to have adequate sample size; $d=0.05$ at $5 \%$ margin of error. Thus, the minimum sample size was calculated to be $384.16 \approx 385$. All the СВСТ images, obtained retrospectively during the period of June 2018 to June 2020 as a part of the examination, diagnosis and treatment planning procedures were 773 . The CBCT images were taken by Rainbow TM CT device (Dentium, South Korea) operating at peak voltage $100 \mathrm{kV}$ and tube current $12 \mathrm{~mA}$, field of view $16 \mathrm{~cm} \times 18 \mathrm{~cm}$, Voxel size $300 \mu \mathrm{m}$, and scan time 20 seconds. The three-dimensional (3D) axial cross sections (coronal, middle, and apical-third root section) were reconstructed using Rainbow TM image viewer software program, version 1.0.0.0 (Dentium, South Korea).

The inclusion criteria were Nepalese nationality, СBCT images with bilateral fully erupted either mandibular first or second molars with closed apexes. Screening identified 571 subjects (288 females and 283 males) with bilateral mandibular first molars (1,142 mandibular first molars) and 623 subjects (313 females and 310 males) with bilateral mandibular second molars (1,246 mandibular second molars) for inclusion in this study.

Three-dimensional CBCT images were displayed for assessment on a 19-inch LCD monitor (DELL) and evaluated by two endodontists (AC and NA). The presence of an extra root was investigated by moving the toolbar from the crown down to the apex in an axial direction. ${ }^{7}$ The cases on which the two endodontists could not reach on consensus were excluded. ${ }^{8,9}$

Data were organised, and entered in Microsoft Excel sheet and analysed using Statistical Package for Social Sciences (SPSS) version 20 (IBM Corp., Armonk, N.Y., USA). The gender ratio, bilateral/unilateral occurrence, correlation between right/leftside and racial variations of the mandibular first and second molars with extra roots were estimated and assessed by Chisquare and Fisher's Exact Test.

\section{RESULTS}

A total of 1,142 mandibular first molars of 571 patients (288 females and 283 males) aged between 16 and 70 years were evaluated in this study. Sixty-five patients (38 females, 27 males) were found to have an extra distolingual root (RE). Overall occurrence of RE was 11.38\% (13.2\% in female, 9.54\% in male). So, on genderwise comparison, it was observed that females had higher number of RE than males.

Out of 38 female patients; the occurrence was 21 (7.3\%) bilateral, 16 (5.56\%) unilateral right side and 1 (0.34\%) unilateral left side. Likewise, out of 27 male patients, the occurrence was 15 (5.3\%) bilateral, 6 (2.1\%) unilateral right side and 6 (2.1\%) unilateral left side. Therefore, on side wise comparison, the bilateral occurrence (Figure 1) was higher than unilateral in both male and female (Table 1).

On racial comparison, out of 65 patients, 50 (14.6\%) were found to be of Mongoloid race and 15 (6.6\%) were found to be of Aryan race (Table 2).

On genderwise comparison, it was observed that females had significantly higher number of RE than males $(\mathrm{P}=0.011)$. Likewise, the occurrence on right side showed statistically significant difference with left side $(\mathrm{P}=0.005)$. On racial comparison, it was found that Mongoloids had significantly higher occurrence than Aryans ( $\mathrm{P}=0.006$, Table 3$)$. No radix paramolaris was found in mandibular first molars.

A total of 1,246 mandibular second molars of 623 patients (313 females and 310 males) were evaluated. Out of 623, bilateral $\mathrm{RE}$ in one male, unilateral RE in four females and unilateral RP (Figure 2) in three females were observed (Table 4).

Table 1: Occurrence of radix entomolaris in mandibular first molars according to gender and side.

\begin{tabular}{|c|c|c|c|c|}
\hline \multirow{2}{*}{ Number of patients } & \multicolumn{2}{|c|}{ Unilateral } & \multirow{2}{*}{ Bilateral } & \multirow{2}{*}{ Total } \\
\cline { 2 - 3 } & Left & Right & & \\
\cline { 2 - 4 } & $\mathrm{n}(\%)$ & $\mathrm{n}(\%)$ & $21(7.3)$ & $38(13.20)$ \\
\hline Female (288) & $16(5.56)$ & $1(0.34)$ & $15(5.3)$ & $27(9.54)$ \\
\hline Male (283) & $6(2.1)$ & $6(2.1)$ & $36(6.3)$ & $65(11.38)$ \\
\hline Total = 571 & $22(3.58)$ & $7(1.2)$ & $72(6.3)$ & $101(8.84)$ \\
\hline No. of total teeth examined (1142) & $22(1.92)$ & $7(0.6)$ & \\
\hline
\end{tabular}

Table 2: Occurrence of radix entomolaris in mandibular first molars according to race.

\begin{tabular}{|c|c|}
\hline Race & $\mathrm{n}(\%)$ \\
\hline Mongoloid (343) & $50(14.6)$ \\
\hline Aryan (228) & $15(6.6)$ \\
\hline
\end{tabular}


Table 3: Comparison of occurrence of radix entomolaris in mandibular first molars according to gender, side and ethnicity (n, \%).

\begin{tabular}{|c|c|c|c|}
\hline Category & \multicolumn{2}{|c|}{ Occurrence } & P value \\
\hline Gender & Female $(38,13.20 \%)$ & Male $(27,9.54 \%)$ & $0.011^{*}$ \\
\hline Side & Right $(22,3.85 \%)$ & Left $(7,1.2 \%)$ & $0.005 \dagger$ \\
\hline Race & Mongoloid (50, 14.6\%) & Aryan $(15,6.6 \%)$ & $0.006 \dagger$ \\
\hline
\end{tabular}

Table 4: Variations in mandibular second molars.

\begin{tabular}{|c|c|c|}
\hline Category & Gender & $\mathrm{n}(\%)$ \\
\hline Bilateral RE & Male & $1(0.1)$ \\
\hline Unilateral RE & Female & $4(0.6)$ \\
\hline Unilateral RP & Female & $3(0.48)$ \\
\hline
\end{tabular}

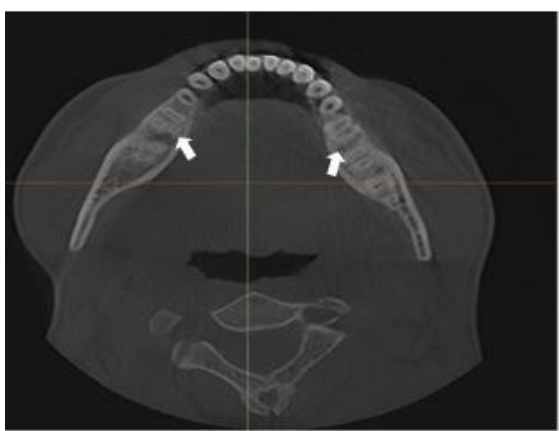

Coronal third root section

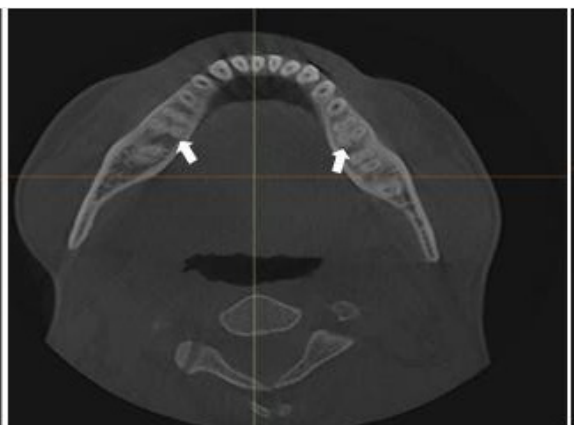

Middle third root section

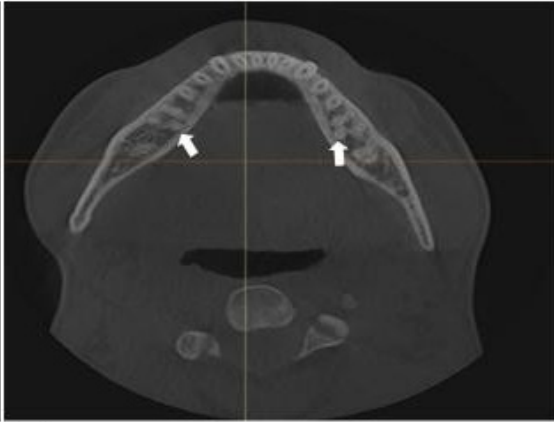

Apical third root section

Figure 1: Bilateral RE in mandibular first molar (white arrow indicating RE).

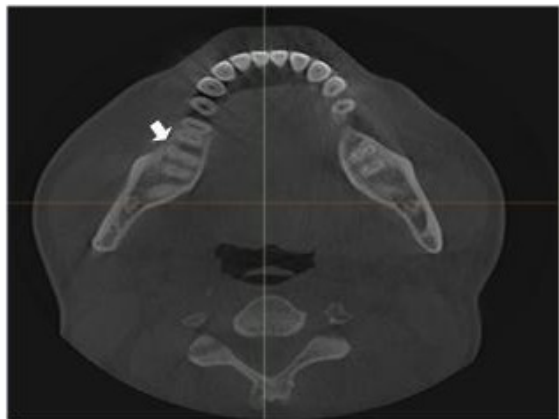

Coronal third root section

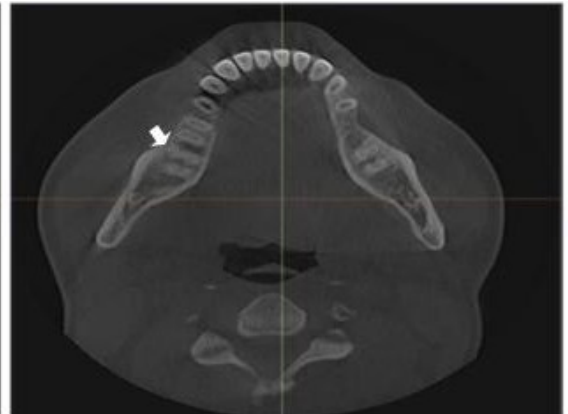

Middle third root section

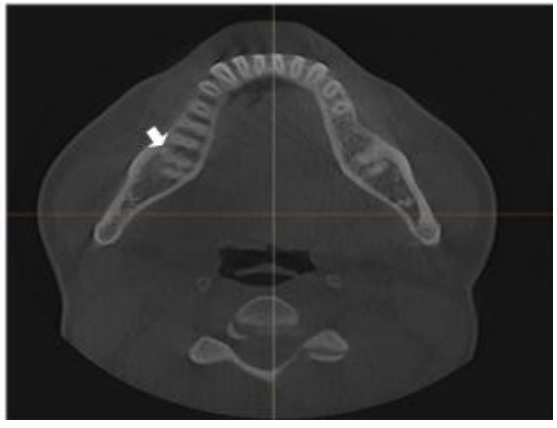

Apical third root section

Figure 2: Unilateral right sided RP in mandibular second molar (white arrow indicating RP).

\section{DISCUSSION}

Knowledge of both normal and abnormal teeth anatomy is utmost important for successful execution of RCT. The outcome of RCT can be improved to great extent by identifying the extra roots and managing all the canals efficiently.,8,80-13 Therefore, clinicians should be aware with the presence as well as the occurrence of teeth abnormalities. ${ }^{14}$ Being the first permanent teeth to erupt, mandibular first molars seem to be the most common teeth seeking RCT and the presence of an extra root (RE or RP) may complicate the endodontic treatment leading to failure because of missed canal.

The RE is located distolingually, with its coronal third completely or partially fixed to the distal root whereas, the RP is located mesiobuccally. The dimensions of these extra roots can vary from a short conical extension to a 'mature' root with a normal length and root canal. This additional root can be separate or nonseparate. ${ }^{4}$ The exact aetiology for the formation of this extra root is still unclear. This can be attributed to some external factors during odontogenesis or due to reappearance of a trait after many generations known as atavism. ${ }^{15}$

In this study, the occurrence of RE in mandibular first molars among central Nepalese population was found to be $11.38 \%$ (13.20\% for female and $9.54 \%$ for male). This figure is similar to the previous studies done in Nepalese population by Garg et al. ${ }^{15}$ and Tripathi et al. ${ }^{16}$ Both studies evaluated intraoral periapical radiographs and concluded the overall occurrence of $12 \%$ and $11.6 \%$ respectively. 
In this study, occurrence of RE was found to be higher in females than males which was statistically significant $(\mathrm{P}<0.05)$ that is similar to the study done by Garg et al. ${ }^{15}$ However, some studies showed no significant differences according to gender. ${ }^{8,16-18}$ In many previous studies, prevalence of RE in first molars were found on right side, ${ }^{8,12,19,20}$ whereas a left side predilection has been reported less frequently. ${ }^{21}$ In this present study, RE was found more frequently on the right side of the assessed CBCT images, whereas in some studies using intraoral radiograph, no side-related significant differences were found. ${ }^{17,18}$ These inter-study contradictory variations might be attributed to differences in the sample size and study methods used, signifying the necessity of further investigations.

Nepal is culturally diverse and multi-ethnic, with many castes under two main races - Aryans and Mongoloids. In this study, occurrence of RE was found to be $14.6 \%$ (50 out of 343) for Mongoloid race and 6.6\% (15 of 228) for Aryan race which was statistically significant $(\mathrm{P}<0.05)$. Radix entomolaris in permanent molars were most frequently found in races of Mongoloid origin. Their incidence has been reported to lie in the range of 5.8 to $43.6 \%$ in Asian populations in contrast to only $0.68 \%$ to $4.2 \%$ among whites. ${ }^{19}$

Radix paramolaris is very rare and occurs less frequently than the RE. In this present study, none of the mandibular first molar showed RP. The prevalence of RP, as observed by Visser, ${ }^{22}$ was found to be $0 \%$ for the first mandibular molar, $0.5 \%$ for the second and 2\% for the third molar. One another study has, however, reported RP in first mandibular molars. ${ }^{23}$

The presence of RE in the mandibular second molar has been reported rarely. In this study, the occurrence of RE was found to be $0.8 \%$ (5 out of 623 ). Study done by Onda et al. ${ }^{24}$ in Japanese cohort found an incidence of $0.38 \%$ and was not seen at all in White and Chinese cohorts. ${ }^{21,25}$ The presence of RP in mandibular second molar, as in our study (3 out of 623, 0.48\%), is much lower. References show that RP in mandibular molars occurs in only $0.5 \%$ of the cases..$^{22}$
Various radiographic images have been used to assess extra roots. Conventional and digital radiographic techniques produces two-dimensional images of three-dimensional objects because of which they have very low accuracy in assessing root morphology and in detecting extra roots. In many studies, conventional CT images (3D) have also been used but the major concern is the radiation dosage. ${ }^{7}$ In the present study, СВCT images have been used as it is considered to be an accurate, noninvasive, and practical method. In addition, images obtained also reveal the true nature of the tooth structures in three dimensions and allow for reliable angulations and measurements.

\section{CONCLUSION}

Occurrence of radix entomolaris in permanent mandibular first and second molars in patients attending tertiary care centre at central Nepal was similar to previous studies in different parts of Nepal. In first molar, the finding is higher in Mongoloid population. However, the radix paramolaris was not found in any of the mandibular first molars and rarely in mandibular second molars. Practitioners should be aware of these unusual variations in root and moreover, extra roots should be diagnosed initially before root canal therapy to facilitate endodontic treatment and to avoid iatrogenic mishap due to missed canal.

\section{ACKNOWLEDGEMENTS}

The authors would like to express sincere gratitude to Dr. Swagat Kumar Mahanta, Department of Community Dentistry, KUSMS for statistical analysis, Professor Dr. Manoj Humagain, and Dr. Harleen Bali for their valuable contribution and continuous support.

\section{Conflict of Interest: None.}

\section{REFERENCES}

1. Vertucci FJ. Root canal anatomy of the human permanent teeth. Oral Surg Oral Med Oral Pathol. 1984 Nov 1;58(5):589-99.

2. Vertucci FJ. Root canal morphology and its relationship to endodontic procedures. Endod Topics. 2005 Mar;10(1):3-29.

3. Bolk L. Comments on root variations in the human lower molar. J Morphol Anthropol. 1915 Jan 1;17(3):605-10.

4. Calberson FL, De Moor RJ, Deroose CA. The radix entomolaris and paramolaris: Clinical approach in endodontics. J Endod. 2007 Jan 1;33(1):58-63.

5. Sperber GH, Moreau JL. Study of the number of roots and canals in senegalese first permanent mandibular molars. Int Endod J. 1998 Mar 1;31(2):117-22.

6. Rahimi S, Shahi S, Lotfi M, Zand V, Abdolrahimi M, Es'haghi R. Root canal configuration and the prevalence of c-shaped canals in mandibular second molars in an iranian population. J Oral Sci. 2008;50(1):9-13.

7. Jayasinghe RD, Li TK. Three-rooted first permanent mandibular molars in a hong kong chinese population: A computed tomographic study. Hong Kong Dent J. 2007;4(2):90-3.

8. Tu MG, Tsai CC, Jou MJ, Chen WL, Chang YF, Chen SY, Cheng HW. Prevalence of three-rooted mandibular first molars among taiwanese individuals. J Endod. 2007 Oct 1;33(10):1163-6.

9. Sabala CL, Benenati FW, Neas BR. Bilateral root or root canal aberrations in a dental school patient population. J Endod. 1994 Jan $1 ; 20(1): 38-42$. 
10. De Moor RJ, Deroose CA, Calberson FL. The radix entomolaris in mandibular first molars: an endodontic challenge. Int Endod J. 2004 Nov;37(11):789-99.

11. Gulabivala K, Aung TH, Alavi A, Ng YL. Root and canal morphology of burmese mandibular molars. Int Endod J. 2001 Jul;34(5):359-70.

12. Gulabivala K, Opasanon A, Ng YL, Alavi A. Root and canal morphology of thai mandibular molars. Int Endod J. 2002 Jan;35(1):56-62.

13. Yew SC, Chan K. A retrospective study of endodontically treated mandibular first molars in a chinese population. J Endod. 1993 Sep $1 ; 19(9): 471-3$

14. Segura-Egea JJ, Jiménez-Pinzón A, Ríos-Santos JV. Endodontic therapy in a 3-rooted mandibular first molar: Importance of a thorough radiographic examination. J Can Dent Assoc. 2002 Oct 1;68(9):541-5.

15. Garg D, Kapoor D. Prevalence of radix entomolaris in population of central region of Nepal: A radiographic study. IP Int J Maxillofac Imaging. 2017 Jun 15;3(2):44-6.

16. Tripathi R, Nepal M, Gautam V, Sah R, Shrestha K, Thapa S. Prevalence of root canal morphology of mandibular molar in western nepalese population: A cross-sectional study. J Univers Coll Med Sci. 2020 Jul 3;8(1):38-41.

17. Schäfer E, Breuer D, Janzen S. The prevalence of three-rooted mandibular permanent first molars in a german population. J Endod. 2009 Feb 1;35(2):202-5.

18. Garg AK, Tewari RK, Kumar A, Hashmi SH, Agrawal N, Mishra SK. Prevalence of three-rooted mandibular permanent first molars among the indian population. J Endod. 2010 Aug 1;36(8):1302-6.

19. Song JS, Choi HJ, Jung IY, Jung HS, Kim SO. The prevalence and morphologic classification of distolingual roots in the mandibular molars in a korean population. J Endod. 2010 Apr 1;36(4):653-7.

20. Garg AK, Tewari RK, Agrawal N. Prevalence of three-rooted mandibular first molars among indians using SCT. Int J Dent. 2013 Jan $1 ; 20(3): 1-6$.

21. Loh HS. Incidence and features of three-rooted permanent mandibular molars. Aust Dent J. 1990 Oct;35(5):434-7.

22. Visser JB. Contribution to the knowledge of human dental root forms. Rotting. 1948;29:49-72.

23. Carlsen O, Alexandersen V. Radix paramolaris in permanent mandibular molars: Identification and morphology. Eur J Oral Sci. 1991 Jun;99(3):189-95

24. Onda S, Minemura R, Masaki T, Funatsu S. Shape and number of the roots of the permanent molar teeth. Bull Tokyo Dental Coll. 1989 Nov 1;30(4):221-31.

25. Tratman EK. Three rooted lower molars in man and their racial distribution. Br Dent J. 1938;64:264-74. 